Conclusions The New Zealand Government has now increased the age that children must use a child restraint to age 7 years. Acceptance of the benefits of booster seats has grown; The Safekids Campaign was also awarded the Traffic Institute of New Zealand (TRAFINZ) leadership award in 2011, which recognises innovation and excellence in contributing to the safety of people on our roads.

\section{TRENDS OF ROAD TRAFFIC CRASHES IN THE UAE: STRATEGIES FOR CONTROL AND PREVENTION}

Mohamed El Sadig. Michal Grivna. Institute of Public Health, College of Medicine and Health Sciences, United Arab Emirates University, UAE.

\subsection{6/injuryprev-2016-042156.368}

Background High rates of serious road traffic crashes (RTCs) have been reported in several Arabian Gulf countries, including the United Arab Emirates (UAE), in recent years. In 2013, in a population of approximately 9.2 million, 7734 people were seriously injured and 651 (7.8\%) died from road traffic injuries (RTI). Hence, the problem constitutes a major concern for public health in the UAE. The study aims to determine the trends of RTI in the UAE, to identify the causal factors of the problem and to review the most cost effective measures to mitigate their impact. Other objectives include estimating the future forecasts of RTI and assessing the economic burden of the problem on the population.

Methods Data from official UAE sources were used for the analysis. To identify RTI trends of morbidity and mortality during 2000-2013, time's series analysis was used. To forecast RTI fatalities in the UAE, regression analysis was used. Analysis of variance (ANOVA) was used to estimate overall and individual significance of regression parameters. To quantify the economic burden of RTI in the UAE, the Human Capital (HC) approach was used to estimate the direct and indirect economic losses from RTI during 2013. For pain, grief and suffering (PGS) willingness to pay value estimates (WTP) were derived worldwide and adjusted for the UAE.

Results The rates of RTC in the UAE were found declining on constant basis. Likewise, trends of morbidity and mortality and future forecasts from RTI were also declining. Paradoxically, however, the severity of RTI was constantly increasing. The total cost of RTIs in the UAE varied between AED 22-23 billion during 2013, representing 1-2\% of its GDP for that year (US\$ 401 billion).

Conclusions Speeding, vehicles' mix, the competency of young drivers, the standard of medical care for victims at the roadside and the efficiency of traffic regulations and measures, are suspected for the paradoxical patterns, but the precise reasons remain to be determined. The study provides a useful base for establishing priorities for future roadway traffic safety interventions in the UAE.

\section{CIVIL SOCIETY SUPPORTING GOVERNMENT IMPLEMENTATION OF CHILD RESTRAINT STANDARDS IN RUSSIA}

Lilia Chibisenkova. Russian Red Cross

10.1136/injuryprev-2016-042156.369
Background In 2014, the Eurasian Economic Community (EvRaZes) Customs Union, approved technical regulations requiring the sale, manufacture and importation of child restraints which conform with UNECE technical regulation 44.04. However, the domestication of these technical regulations has been slowed.

Description of the problem Children are dying on Russian roads. In 2014, 9302 car crashes involved children, and of those, 551 resulted in the death of children. Russia lacks child restraint policies which would mandate the sale, manufacture and use of child restraints which conform with international safety standards. In 2015, the Russian Red Cross conducted a poll showing that more than $96 \%$ of parents support using safe child restraints. A subsequent market survey showed that about $80 \%$ of child restraints sold in the Russian Federation, do not comply with the UNECE R44/04 requirements.

Results The adoption and implementation of UNECE R44/04 in Russia requires significant political will. Administrative and technical codes must be revised by a number of key ministries and government agencies. Following the poll and market survey findings, the Russian Red Cross worked with the relevant ministries and key government entities, including Presidential Commission on Human Rights, and media to call for the strengthening of child restraint policies in Russia and domestication of EvRaZes technical regulations. In August 2015, First Deputy Prime Minister of Russia, Igor Shuvalov, ordered all relevant government agencies and ministries to implement the standards.

Conclusions The Russian Red Cross effectively used their research findings to partner with the government and speed up the implementation of safe child restraints.

\section{SCHOOL TRANSPORT IN URUGUAY}

${ }^{1}$ Florencia González, ${ }^{2}$ Valeria Motta. ${ }^{1}$ Fundación Gonzalo Rodríguez, Uruguay; ${ }^{2}$ Fundación Gonzalo Rodríguez, Uruguay

\subsection{6/injuryprev-2016-042156.370}

Background (issue/problem) The Act for the creation of the National Road Safety Agency (UNASEV) and another act related to traffic provisions were passed in 2007. Although this represented some progress in Road Safety, children's needs were not taken into account. Fundación Gonzalo Rodríguez (FGR), organisation focused on Child Road Safety, was concerned about this fact. Aware that safety conditions were below acceptable levels, the FGR promoted research on private and School Transport equipment.

Results showed that seats in use were unstable, did not have headrests or seat belts, and retrofitting was impossible.

These findings generated alliances with different organisations in order to develop a feasible technical proposal to promote a change that considered the safety needs of children as vulnerable road users.

Description of the problem

Together with a renowned car manufacturer and a child seat manufacturer, a feasible proposal was presented including tax benefits. Said proposal was presented with the support of the School Transport Union, UNASEV, the Deputies Chamber of Transport, the Ministry of Economy and Finance and the President of the Republic, Dr. Tabaré Vázquez.

Results (effects/changes) The whole School Transport fleet in Montevideo (Uruguay) was replaced. 